\title{
Impactos e afinidades do conceito de “ambiente" em textos literários cabo-verdianos e brasileiros: uma reflexão sobre a literatura na relação com a experiência traumática Impacts and affinities of the concept of "ambiance" in Cape Verdean and Brazilian literary text: a reflection on literature in relation to the traumatic experience
}

Simone Caputo Gomes*

RESUMO: COM BASE NA TOPOANÁLISE DE TEXTOS LITERÁRIOS E MUSICAIS (POESIA POPULAR), ESTE ENSAIO PRETENDE DESENVOLVER UMA REFLEXÃO SOBRE O RENDIMENTO DE CATEGORIAS TEÓRICAS COMO AMBIENTE, CATÁSTROFE, EXPERIÊNCIA DE CHOQUE, TRAUMA E CRIPTA PARA A LEITURA COMPARATIVA DE PRODUÇÕES CABO-VERDIANAS E BRASILEIRAS.

ABSTRACT: BASED ON THE TOPOANALYSIS OF LITERARY AND MUSICAL (POPULAR POETRY) TEXTS, THIS ESSAY ATTEMPTS TO DEVELOP A REFLECTION ABOUT THE PROFIT OF THEORETICAL CATEGORIES SUCH AS THE ENVIRONMENT, THE CATASTROPHE, THE EXPERIENCE OF SHOCK, TRAUMA AND THE CRYPT FOR A COMPARATIVE READING OF CAPE-VERDEAN AND BRAZILIAN PRODUCTIONS.

PALAVRAS-CHAVE: LITERATURA CABO-VERDIANA; LITERATURA BRASILEIRA; ESPAÇO/AMBIENTE; CATÁSTROFE; TRAUMA; CRIPTA.

KEYWORDS: CAPE-VERDEAN LITERATURE; BRAZILIAN LITERATURE; SPACE/ ENVIRONMENT; CATASTROPHE, TRAUMA, CRYPT.

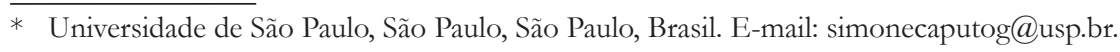


O sol dava a impressão de ferver a terra. A mormaceira era de tirar a respiração. O pessoal estirava-se debaixo das paredes, a fugir da calmaria. As mulheres com meninos pelos braços, estendiam-se no chão, enquanto os filhos choravam pedindo comida, batendo-lhe com as mãos. [...] Então, o número de mortos crescia. As sepulturas recebiam os corpos, engolindo-os para se acabar com os vestígios da Inanição que invadira a Ilha.

(Luís Romano, Cabo Verde)

Quando olhei a terra ardendo

Qual fogueira de São João

Eu perguntei a Deus do céu, ai

Por que tamanha judiação

Que braseiro, que fornalha

Nem um pé de plantação

Por falta d'água perdi meu gado

Morreu de sede meu alazão

Até mesmo a asa branca

Bateu asas do sertão

Então eu disse, adeus Rosinha

Guarda contigo meu coração

(Humberto Teixeira, Brasil)

poema-canção "Asa Branca", que apresento como reminiscência - e tomo como ponto de partida da minha reflexão sobre uma leitura possível das séries literárias brasileira e cabo-verdiana -, de autoria do cearense Humberto Teixeira (música do pernambucano Luiz Gonzaga), remonta à zona do Cariri, onde a seca se instala periodicamente no nordeste brasileiro. A asa branca é uma das aves que, na crendice popular, através de suas arribadas da região, indicam que é chegada a hora de o sertanejo partir, porque a seca se aproxima. Ao abandono da terra pela asa branca corresponde o êxodo dos retirantes sem esperança de chuva. Esse quadro melancólico, de 1947, sensibilizou os dois nordestinos famosos e o resultado foi o clássico da música e da poesia popular brasileira, composto a partir de versos extraídos da tradição oral do Cariri. 
Outras artes, como a literatura e a pintura, têm tomado o espaço como um índice diferenciador das várias regiões do Brasil. O crítico Antonio Candido, em Formação da literatura brasileira: momentos decisivos, afirma:

O nosso romance tem fome de espaço e uma ânsia topográfica de apalpar todo o país. Talvez o seu legado consista menos em tipos, personagens e peripécias do que em certas regiões tornadas literárias, a sequência narrativa inserindo-se no ambiente, quase se escravizando a ele (2007, p. 433, grifos meus).

No que toca a Cabo Verde, um refrão das minhas aulas, que aqui inscrevo, é a percepção de que a literatura cabo-verdiana é primordialmente uma literatura que "tem fome de espaço". O arquipélago e o ambiente (títulos de obras do cabo-verdiano Jorge Barbosa) são transfigurados literariamente à exaustão, em seus sítios diversificados (Paúl, Cidade Velha, Mindelo, Monte Cara, Porto Grande, Sotavento, Barlavento etc). Obra incontornável sobre essa apreensão do espaço do arquipélago é Nascimento de um mundo (1991), do poeta Mário Lúcio Sousa, que representa a gênese de Cabo Verde e particulariza cada ilha em suas especificidades.

Essa preocupação com o espaço (tornado "ambiente" no seu impacto sobre o humano, como propõe Antonio Candido) confirma uma tendência formal cada vez mais consolidada nas duas séries literárias que agora examino. $\mathrm{Na}$ literatura brasileira, sobretudo nas décadas de trinta e quarenta do século $\mathrm{XX}$, com o denominado regionalismo brasileiro. Graciliano Ramos, em Infância: memórias (1952, p. 22), dá o seguinte depoimento sobre a paisagem que retratou em Vidas Secas, romance de 1938:

Desse antigo verão que me alterou a vida restam ligeiros traços apenas. E nem deles posso afirmar que efetivamente me recorde. O hábito me leva a criar um ambiente, imaginar fatos, a que atribuo realidade. Sem dúvida as árvores se despojaram e enegreceram, o açude estancou, as porteiras dos currais se abriram, inúteis. É sempre assim. [...]. Dificilmente pintaríamos um verão nordestino em que os ramos não estivessem pretos e as cacimbas vazias. Reunimos elementos considerados indispensáveis, jogamos com eles [...] (RAMOS, 1952, p. 22, grifos meus). 
O escritor brasileiro tem consciência do processo de representação como construção de uma paisagem literária sertaneja, vinculada com recorrência à imagem das secas, catástrofes ocorridas no Brasil, principalmente em 1934 e 1936 (período próximo à publicação de Vidas secas), entre 1979 e 1985, em 1997 e 1999, em 2011 (quando cento e setenta e nove municípios nordestinos entraram o ano em estado de emergência em virtude da estiagem, sendo oitenta e um localizados no Ceará).

Antonio Candido (no ensaio "Degradação do espaço", 1972), Osman Lins (em Lima Barreto e o espaço romanesco, 1976) e Georges Poulet (na obra O espaço proustiano, 1992) são unânimes em correlacionar o espaço e a atuação das personagens no texto literário: numa narrativa bem construída, as personagens vestem o cenário, identificando-se com ele (POULET, 1992, p. 31), em simetria e sintonia. Transfiguram-no, afinal, em ambiente. A um espaço desértico, por exemplo, em Vidas secas, de Graciliano Ramos, ou nos "Poemas da cabra", de João Cabral de Melo Neto (1975, p. 114-122), correspondem temperamentos secos das personagens, falas guturais, escassez de vocabulário em similitude à carência de recursos materiais de um Fabiano ou do "cabra" Severino, de vida e morte extremamente "severas".

Na série literária cabo-verdiana, Dina Salústio, em "Traição do tempo", produto híbrido de conto e crônica temperado com ritmos e processos artísticos de poesia, resume os "humores do crioulo" na correlação com "uma incógnita que há muito deixou de o ser para tomar o corpo de uma certeza" (1994, p. 61) - a estiagem:

O crioulo, a partir de Junho, começa a incubar dentro de si um ser ruim, desconfiado, medroso, inseguro. E à medida que os dias passam e os meses entram e saem, os olhos ficam enviesados entre o céu e a terra, os lábios desaparecem nos encovados do rosto, resmungando por tudo e nada sobre a ingratidão as chuvas, a maldição das ilhas, os pecados cometidos. Traído, porque as nuvens maninhas mais uma vez cumpriram o seu destino de negar à terra o consolo da água, o crioulo enraivece-se contra tudo o que o rodeia. Torna-se insuportável de tão intolerante, tão feio, tão desamado. [...]

As ruas, os espaços, o tempo tornam-se violentamente agressivos. $\mathrm{E}$ o crioulo com eles.

Eu fujo dos meus patrícios nos meses das águas frustradas. Eu fujo de mim. [...] 


\section{Somos todos uma ameaça coletiva, de tanta tristeza. [...] a cidade seca, as gentes secas, os amores secos (Ibidem, p. 61-62, grifos meus).}

Destaco que o texto salustiano alia o trágico e a violência ao asco ("as moscas e a imundícia alastram-se", Ibidem, p. 62), encontrando no grotesco uma via que será radicalizada, por exemplo, em Famintos (1962), de Luís Romano, cabo-verdiano que viveu por muito tempo no Brasil (Natal, Rio Grande do Norte), conhecendo bem, portanto, os dois espaços desérticos sobre os quais as obras que ora apresento se debruçam: as ilhas crioulas e a caatinga brasileira. Único bioma exclusivamente brasileiro (e o mais fragilizado deles, pelo uso insustentável de seus solos e recursos naturais ao longo de centenas de anos de ocupação), a caatinga ${ }^{1}$ corresponde à vegetação durante o período de estiagem, quando a maioria das plantas perde as folhas e os troncos tornam-se esbranquiçados e secos. Ocupa uma área de cerca de 10\% do território brasileiro $(800.000 \mathrm{~km})$ e sua parte mais seca, com chuvas irregulares ao longo do ano e vegetação mais rústica, denomina-se sertão ${ }^{2}$.

Tal paisagem é familiar à maioria dos cabo-verdianos, que nos anos quarenta do século vinte chegaram a enfrentar secas de até seis anos, segundo António Carreira (1984), ambiente impactado ainda pela Segunda Guerra Mundial (1939-45) e pelo desinteresse do governo colonial em melhorar as condições de vida do arquipélago. Ao lado da ferida na terra seca, acrescentava-se a "cicatriz fascista" (Corsino Fortes, 2001, p. 161). Cicatriz sobre cicatriz.

Trilhando essa rota de leitura, posso citar inúmeros textos cabo-verdianos e brasileiros que se correlacionam diretamente e que dão uma amostra das possibilidades de ler de outra maneira a reencenação do trauma da seca: "Asa Branca" e Nha terra skalabróde, no poema-canção; os romances Famintos (de Luís Romano), Flagelados do vento leste (de Manuel Lopes) e Vidas Secas (de Graciliano Ramos), assim como Chiquinho (de Baltasar Lopes) e O Quinze (de Rachel de Queiroz) ou Menino de Engenho (de José Lins do Rego); os contos "Dragão e eu" (de Teixeira de Sousa) e o citado "Traição do tempo" (de Dina Salústio); os poemas "Triste regresso" (de Eugénio Tavares) em interface com

1. O termo caatinga deriva do tupi: caa (mata) + tinga (branca).

2. Ou Depressão Sertaneja Setentrional, que ocupa desde a fronteira norte de Pernambuco, estendendo-se pela maior parte dos Estados da Paraíba, Rio Grande do Norte e Ceará, prolongando-se até uma pequena faixa ao norte do Piauí. 
"A triste partida", de Patativa do Assaré, complementados por "Paisagem" e "Casebre" (de Jorge Barbosa), "Quotidiano" (do livro Terra Gritante, de Luís Tolentino), "Chuva" e "Chão do povo, chão de pedra" (de Corsino Fortes).

E acrescento os "Poemas da Cabra", de João Cabral de Melo Neto em diálogo com a "Homenagem em forma de cabra" (de Daniel Filipe) e com os poemas de Arménio Vieira dedicados àquele autor brasileiro ("Toti Cadabra" e "Dez poemas mais um"), além das telas de Portinari ("Retirantes", "Criança morta" e "Enterro na rede") e de Kiki Lima ("Resistência"), inspiradas respectivamente em Vidas secas e Flagelados do vento leste (de Manuel Lopes), com releituras poéticas de Ovídio Martins (em poema homônimo) e de Corsino Fortes ${ }^{3}$.

A experiência do choque ou, melhor dizendo, da catástrofe, constitui um maná, ferida recalcada ou poço sangrento ("o poço mais raso das nossas lesões", sintetiza Corsino Fortes, 2001, p. 35) que tudo tinge de vermelho e de onde se vai resgatar a experiência do horror: a terra ardendo qual fogueira de São João, a(s) ilha(s) a ferver, "terra gritante" (TOLENTINO, s.d.) porque nela ecoa a voz ou o "silêncio estrangulado nas goelas" (FORTES, 2001, p. 35) de seres humanos expostos ao paroxismo:

$\mathrm{Na}$ planície avermelhada os juazeiros alargavam duas manchas verdes. Os infelizes tinham caminhado o dia inteiro, estavam cansados e famintos. [...] Fazia horas que procuravam uma sombra. A folhagem dos juazeiros apareceu longe, através dos galhos pelados da caatinga rala. [...]

Miudinhos, perdidos no deserto queimado, os fugitivos agarraram-se, somaram as suas desgraças e os seus pavores. O coração de Fabiano bateu junto do coração de Sinhá Vitoria, um abraço cansado aproximou os farrapos que os cobriam. Resistiram à fraqueza, afastaram-se envergonhados, sem ânimo de afrontar de novo a luz dura, receosos de perder a esperança que os alentava [...].

[Fabiano] Espalhou a vista pelos quatro cantos. Além dos telhados, que lhe reduziam o horizonte, a campina se estendia, seca e dura. Lembrou-se da marcha penosa que fizera através dela, com a família, todos esmolambados e famintos (RAMOS, 1981, p. 53, grifos meus).

\footnotetext{
3. São cabo-verdianos: Luís Romano, Manuel Lopes, Teixeira de Sousa, Dina Salústio, Eugénio Tavares, Jorge Barbosa, Luís Tolentino, Corsino Fortes, Daniel Filipe, Arménio Vieira, Kiki Lima, Ovídio Martins, por ordem de citação.
} 
Os ecos ou gritos estrangulados do texto brasileiro reverberam em Famintos, de Luís Romano (romance publicado em 1962), numa das epígrafes de nosso ensaio. Observemos um "quadro" (como o próprio Romano define o excerto) do romance:

Então o sol começou a queimar, a estorricar tudo com o poder de fogo, abrindo rachas na terra que fora molhada parcamente, dias antes. Os pinguinhos de água, como pérolas vivas, nas caravelas das plantinhas, secaram (ROMANO, 1962, p. 174).

Relembremos outras passagens desse veio temático traumático sempre renovado nas duas literaturas, como as variações de uma fuga de Bach.

Em 1900, Eugénio Tavares já refere a catástrofe que atinge a sua amada ilha Brava (convertida em Vênus que a paixão do Sol devora), em poema alusivo à volta do emigrado:

Triste Regresso

$$
\text { A José Bernardo Alfama }
$$

Dentro da claridade plúmbea da manhã

A Ilha, sobre o mar, lembra uma catedral.

As nuvens em silêncio imergem devagar

Qual um fumear de incenso

Num ascetismo intenso,

Num perfume subtil de velha fé cristã.

Pelas naves glaciais da brônzea catedral.

A Ilha, sobre o mar.

E sobem vagamente em lágrimas banhando

\section{A dura fronte augusta e grave dos rochedos.}

Bebe em fundo silêncio a terra fulva, adusta.

\section{A lágrima que cai;}

E a nuvem passa, vai.

Numa insondável mágoa imensa rorejando.

Em gélido suor, dos túrbidos rochedos

\section{A dura fronte augusta.}


Mas, já da opa cinzenta a Ilha se desnuda.

Beija-a com fúria o sol, dentes de fogo a comem.

$O$ vento reduziu-lhe a trapos o lençol.

Emerge, e se acentua.

Do mar, móvel, nua,

Transida de tristeza, em uma angústia muda...

$\mathrm{E}$, enquanto ao longe as nuvens álgidas se somem

Beija-a com fúria o sol.

Da c'roa do platô à fímbria da leveza

As árvores sem vida estorcem-se de sede.

E o sol - bem como um rei fanático, homicida, -

Fustiga-as a matar.

E ri-se ao incendiar

Os ramos - como mãos erguidas de quem reza -

$\mathrm{E}$ as folhas - como mãos abertas de quem pede -

Das árvores sem vida.

Em fim, o meu Navio, aos poucos, se aproxima.

Nos tristes olhos meus em lágrimas, rebrilha

A dita de ancorar após mil escarcéus.

$E$, pois que as nuvens vão

Fugindo na amplidão

Sem que uma gota de água enviem lá de cima.

Darei à tua sede o pranto - oh minha Ilha!

Dos tristes olhos meus. (TAVARES, 1996, p. 75, grifos meus)

O poema "A triste partida", do poeta popular cearense Patativa do Assaré, pode ser encarado como o oposto complementar brasileiro do texto caboverdiano, aludindo tanto ao flagelo da seca, quanto à emigração forçada, ao descaso das autoridades e à exploração: 
A Triste Partida

Meu Deus, meu Deus.

Setembro passou

Outubro e Novembro

Já tamo [estamos] em Dezembro

Meu Deus, que é de nós,

Meu Deus, meu Deus

Assim fala o pobre

Do seco Nordeste

Com medo da peste

Da fome feroz

Ai, ai, ai, ai [...]

Rompeu-se o Natal

Porém barra não veio

O sol bem vermeio [vermelho]

Nasceu muito além

Meu Deus, meu Deus [...]

\section{Sem chuva na terra}

Descamba Janeiro,

Depois Fevereiro

E o mesmo verão

Meu Deus, meu Deus

Entonce [então] o nortista

Pensando consigo

Diz: "isso é castigo

não chove mais não"

Ai, ai, ai, ai [...]

Agora pensando

Ele segue outra tria

Chamando a famia [família]

Começa a dizer 
Meu Deus, meu Deus

Eu vendo meu burro

Meu jegue e o cavalo

Nós vamos a São Paulo

Viver ou morrer

Ai, ai, ai, ai [...]

Em um caminhão

Ele joga a famia [família]

Chegou o triste dia

Já vai viajar

Meu Deus, meu Deus

A seca terrível

Que tudo devora

Lhe bota pra fora

Da terra natá [natal]

Ai, ai, ai, ai $[\ldots]$

Trabaia [Trabalha] dois ano,

Três ano [anos] e mais ano

E sempre nos prano [planos]

De um dia vortar [voltar]

Meu Deus, meu Deus

Mas nunca ele pode

Só vive devendo

$\mathrm{E}$ assim vai sofrendo

É sofrer sem parar

Ai, ai, ai, ai $[\ldots]$

Distante da terra

\section{Tão seca mas boa}

Exposto à garoa

À lama e o paú [paul]

Meu Deus, meu Deus

Faz pena o nortista 
Tão forte, tão bravo

Viver como escravo

No Norte e no Sul

Ai, ai, ai, ai ${ }^{4}$

Para a corrente do estudo da Geografia denominada perspectivismo, a ação do sujeito, os processos e os contextos espaciais específicos substituem o conceito positivista de espaço absoluto: é o sujeito cultural, político, social que dá sentido ao espaço, assim tornado "ambiente”. Para Milton Santos (2008), mesmo o espaço físico não deixa de ser uma construção. Dessa forma, a topoanálise, na literatura, na música e na pintura, poderá ser uma linha de leitura fértil para a arte elaborada a partir de quadros ou cenas de catástrofe, como a da seca, tanto no nordeste brasileiro quanto nas ilhas de Cabo Verde.

Esse filão tem sido bastante e, não raro, superficialmente estudado na série literária cabo-verdiana (redundando durante longo tempo somente sobre textos literários que, coincidentemente, têm edições brasileiras), sobretudo em diálogos como os da moderna ficção regionalista brasileira com a produção da primeira geração da Claridade ou da poesia de João Cabral com a de Corsino Fortes.

Retomo também essas pontas, dentre outras, por considerar a importância das obras citadas, mas lançando sobre elas um outro olhar, que elucida talvez a minha decisiva escolha de dedicar trinta e sete anos ao estudo da literatura de uma segunda pátria que assumi, plantada nas ilhas de "Filhos do Sol", como refere Leila Hernandez (2002).

Tem vindo à tona recentemente, nos estudos sobre as relações entre Literatura e História, as consequências para o psiquismo humano das situações (espaço-ambientais) catastróficas que se têm apresentado ao homem. Jaime Ginzburg esclarece: "Para o entendimento das relações entre Literatura e História, é fundamental considerar a importância dos traumas históricos como motivação para mudanças nos modos de representação literária, tanto na Europa como no Brasil" (2000, p. 3). No ensaio "A história como trauma", centrado na reflexão sobre a literatura que tematiza o Holocausto, Márcio Seligmann-Silva (2000) desenvolve uma discussão sobre a consolidação dos gêneros híbridos e sobre a problematização da noção de representação, as-

4. Respeitando a linguagem popular usada pelo poeta, grifos meus. Disponível em: <http://www. usinadeletras.com.br/exibelotexto.php? $\operatorname{cod}=7813 \&$ cat $=$ Cordel\&vinda $=S>$. 
sociadas à experiência do choque na vida moderna. O teórico propõe que expressar a experiência da catástrofe nas proporções que ela assumiu no século $\mathrm{XX}^{5}$ implica uma renúncia aos modos convencionais de representação, incapazes de preservar a perplexidade da experiência.

O problema psicanalítico do trauma converte-se, assim, num problema estético (SELIGMANN-SILVA, 2000, p. 122) e a literatura de trauma vai resgatar um evento latente na memória, tentando, incessantemente, representar o irrepresentável. Um excesso de realidade alia-se ao testemunho de uma falta, que corresponde à impossibilidade de recobrir o vivido com o verbal. Nicolas Abraham e Maria Torok (1972, p. 245) usam uma metáfora que considero fulcral para caracterizar a origem do processo de introjeção do trauma: "uma comunhão de bocas vazias". O primeiro paradigma da introjeção, para os autores, consiste em aprender a preencher o vazio da boca com palavras (Ibidem, p. 246.) Segundo Abraham \& Torok:

Introjetar um desejo, uma dor, uma situação, é fazê-los passar pela linguagem numa comunhão de bocas vazias. É assim que a absorção alimentar, no sentido próprio, se torna a introjeção no figurado. Operar essa passagem é conseguir que a presença do objeto dê lugar a uma auto-apreensão de sua ausência. A linguagem que supre essa ausência, figurando a presença, só pode ser compreendida no seio de uma 'comunidade de bocas vazias' (Ibidem, p. 246, grifos meus).

Continuando a discussão, os psicanalistas edificam o conceito de "cripta", representada pela conservação de uma experiência indizível no interior do psiquismo de um sujeito ou de uma coletividade:

Todas as palavras que não puderam ser ditas, todas as cenas que não puderam ser rememoradas, todas as lágrimas que não puderam ser vertidas, serão engolidas, assim como, ao mesmo tempo, o traumatismo, causa da perda. Engolidos e postos em conserva. O luto indizível instala no interior do sujeito uma sepultura secreta.

\footnotetext{
5. Com as Guerras Mundiais, as bombas atômicas em Hiroshima e Nagasaki, os genocídios na Alemanha, no Tibet, no Cambodja, em Kosovo, em Ruanda, e completando, as catástrofes do século XXI, elencando o episódio das Torres Gêmeas e o genocídio em Darfur.
} 
$\mathrm{Na}$ furna repousa, vivo, reconstruído a partir de lembranças de palavras, de imagens e de afetos, o correlato objetal da perda, [...] bem como os momentos traumáticos - efetivos ou supostos (Ibidem, p. 249, grifos meus).

O reconhecimento do sofrimento por um terceiro permite sua assimilação, centrando a experiência na relação do indivíduo com o ambiente.

Faço aqui uma pausa e volto ao começo do meu texto, que partia da profunda comoção que me causa, desde a infância, a audição de "Asa Branca" e o sentimento de com-paixão ${ }^{6}$ face aos relatos sobre as secas prolongadas que sempre atingiram o Ceará. Recordo ainda o impacto da leitura de Vidas secas, já adolescente, e a raiva do Soldado Amarelo, assim como o meu sofrimento juntamente com a família do sertanejo Fabiano. Mais tarde, o encontro com Cabo Verde, a partir da poesia de Daniel Filipe, continuando esse percurso de emoções estéticas que eu partilhava, sobretudo por admirar a capacidade daqueles artistas em expor em palavras o horror, que me parecia indizível, das catástrofes das secas e das fomes consequentes.

Esse fluxo poético-narrativo, comum e vivo, que contagiou tantas gerações brasileiras e cabo-verdianas, acabou também por impactar-me na medida em que, como nos ensina Walter Benjamin (1983, p. 33), a arte, ao reviver o trauma, recupera o terreno da experiência poética pela memória involuntária, que se nutre de resíduos que resistem ao esquecimento. Narrar o trauma abre caminho à sua superação, com a certeza de que, "no sangue das palavras/ há pistas para óvnis” (Corsino Fortes 2001, p. 123). Acrescenta Seligmann-Silva (2008, p. 71) que:

Da Ilíada a Os sertões, de Édipo Rei (Sófocles, [500 BC.] 1982) à Guernica (Picasso, 1937), de Hamlet (Shakespeare, [1602] 1936) ao teatro pós-Shoah de um Beckett, podemos ver que o trabalho de introjeção da cena traumática praticamente se confunde com a história da arte e da literatura.

A arte consiste, sob essa ótica, numa espécie de escudo de Perseu, em que o ser humano pode mirar os olhos da Górgona ${ }^{7}$ sem se transformar em pedra ou em laje tumular de mutismo. No caso da Literatura, o escritor consegue dar voz

6. Capacidade de me emocionar com.

7. Medusa, figuração da morte. 
a experiências que, provavelmente, os sobreviventes a elas não conseguiriam verbalizar, por excesso de choque; inscreve (escreve) sobre a lápide muda:

Talvez a busca deste local do testemunho seja antes uma errância, um abrir-se para sua assistematicidade, para suas fraturas e silêncios. É na literatura e nas artes onde esta voz poderia ter melhor acolhida, mas seria utópico pensar que a arte e a literatura poderiam, por exemplo, servir de dispositivo testemunhal para populações como as sobreviventes de genocídios ou de ditaduras violentas. Mas isto não implica, tampouco, que nós não devamos nos abrir para os hieróglifos de memória que os artistas nos têm apresentado. Podemos aprender muito com eles (SELIGMAN-SILVA, 2008, p. 78, grifos meus).

Quando Luís Romano, em Famintos: romance de um povo (1962), reencena perdas coletivas que concorrem para o sentimento de desamparo humano e acabam por, como enfatiza Bohleber (2000, p. 817), chocar várias gerações que se identificam com as experiências traumáticas dos pais, avós e bisavós, é possível associar a memória do trauma ao sentimento de "cripta", que Abraham e Torok abstraem das famílias dizimadas pela Segunda Guerra. Lembro ainda que o fenômeno da estiagem, em Cabo Verde, como ressalva Manuel Ferreira no prólogo a Terra trazida: contos (1972), assim como no sertão brasileiro, é cíclico, dele resultando "o equilíbrio destruído", a "tragédia da fome. Fome oculta, fome crónica, fome epidémica, fome total" (FERREIRA, 1972, p. 8).

Transferindo (ou traduzindo) o conceito dos psicanalistas húngaros para o contexto cultural cabo-verdiano, à luz do texto Terra trazida, de Manuel Ferreira (1972), essa "identificação endocríptica" ou "decantação topográfica" tem como detonador a "longa odisseia, dezenas de milhar caídos de morte morrida, morte matada" (Ibidem) e que "podia ter sido, e vezes sem conto, ao longo do século XVII, do século XVIII, do século XIX, do século XX “ (Ibidem, p. 9). Esse processo de identificação é fulcral para os desdobramentos da concepção do trauma numa teoria da memória incorporada, porque provoca um estancamento do fluxo temporal que parece congelar experiências enterradas vivas (ABRAHAM \& TOROK, 1995, p. 223), individuais ou coletivas, transformando-as numa cripta ou monumento a que incessantemente se retorna, para melhor elaborá-las e ultrapassá-las.

Os poemas "Casebre" e "Paisagem", de Jorge Barbosa, "Quotidiano", de Luís Tolentino, "Chuva" e "Chão do povo, chão de pedra", de Corsino Fortes, 
erigem como simbólicos do trauma ícones como "a padiola mortuária da regedoria", a "barriga inchada" das crianças, o fogão tradicional de três pedras inativo (BARBOSA, 1956, p. 28), panelas "mortas/vivas/nos fogões apagados" e "pilões calados" (FORTES, 2001, p. 37), "enxadas esquecidas nos cantos dos quintais" (BARBOSA, 2002, p. 59); "pote quebrado/ bidom vazio" (TOLENTINO, s.d., p. 14). Essa literatura de "identificação endocríptica", como ressalva Seligmann-Silva (1998, p. 22), implica, portanto, uma nova ética da representação e uma nova estética caracterizada pela presença de imagens mudas que exigem uma diversa performance da linguagem: "essa ética e estética da literatura de testemunho possui o corpo - a dor - como um dos seus alicerces" (CY'TRYNOWICZ, 2003, p. 133-134) para a reencenação do trauma, da ferida na memória, a fim de abrir a possibilidade de um futuro.

Como ressalta Luís da Câmara Cascudo na apresentação a Famintos, o "romance do povo cabo-verdiano" expressa-se numa "linguagem forjada em sangue" (Ibidem, s. p), similar à "poeira levantada pelo vento" que transforma "o campo num mar de ocra, cor de tijolo" (Ibidem, p. 13). Para o brasileiro, Luís Romano "testemunha" mais do que panfleta e seu livro mostra "os homens sofrendo mais a fome da piedade do que a falta de pão" (Ibidem). Famintos canta o "povo-de-pé-descalço" (p. 85) da Ilha-sem-nome (p. 328), numa "Toada Proibida" (pela polícia) que é simbolizada pelo "violão", sinônimo do "povo inteiro que está na agonia" (p. 86):

[...] faz gente homem arripiar cabelo da cabeça: é silêncio de casa deserta de gente, é trepidação de picareta, é lanho de chicote de polícia, e de Mulato no lombo de desgraçado, é agonia de gente velha acabando como morraça no lume, é homem de trabalho morrendo como cachorro cheio de coceira, é criatura a pedir esmola e esticando na porta da igreja, é barulho de boca pisando milho cru (Ibidem).

O horror e o grotesco, assim como a forma descosturada dos "quadros" do romance, impõem-se de pronto na "Carta" inicial que Romano dirige ao "Irmão" leitor, apelando para identificação endocríptica semelhante à que motivou o autor: "Que as cenas que vais ler neste livro retenham tua sensibilidade, como tam profundamente se estamparam no meu íntimo./Que nelas encontre o teu drama - o drama de nós todos" (Ibidem, p. 11). Dentes partidos, fatos esfarrapados, excrementos a manchar as roupas, leprosos, homens 
ganindo como cachorros, estalos de chicote, mulheres em pele e osso, crianças berrando sem parar, velhos carregando a sua "pobreza envergonhada que esmola" esperando o vapor da Terra-Longe, dormindo para enganar as cãibras do estômago, jovens se prostituindo em troca de um prato de comida, de mistura com "a secura de endoidecer" de anos sem chuva (Ibidem, p. 21) compõem as cenas dantescas que culminam na morte de muitos.

O grotesco e o abjeto, expressos tanto por Luís Romano em Famintos quanto por Teixeira de Sousa no conto "Dragão e eu" (1960), processam-se numa espécie de arte-ação (KRISTEVA, 1980, p. 89), resultado de um gestus (Ibidem, p. 180) que brota continuamente, como lava que jorra duma fenda ou como secreção ("laivos de sangue", Ibidem, p. 19) que irrompe de uma ferida. A encenação repete-se, como prova da ferida do trauma (FORSTER, 1996, p. 132 e 157) e como um não-sentido que oprime e que excede a representação.

Do exposto, posso inferir que a literatura cabo-verdiana, assim como a produção brasileira do sertão, reencena as sucessivas catástrofes provocadas pelas longas estiagens para tentar entender e representar o trauma ambiental que impacta o ser humano. Retratar, numa comunhão de bocas vazias, os seios da cabra e da terra literalmente secos, corresponde ao processo de introjetar o trauma para, tomando dele consciência e verbalizando-o, poder ultrapassá-lo: encontrar a seiva e o verde, "fartas de fome \& famintas de fartura" (FORTES, p. 240). "De pé sobre a pedra [ou cripta] do drama" (Ibidem, p. 203), ao deglutir o trauma e o fantasma da fome, "as ilhas/ perdendo peso / ganharam asas" (Ibidem, p. 107). Seu povo, mesmo tendo sido, "já não será mais flagelado do vento leste" (Ibidem, p. 202).

Nessa trajetória, a série literária cabo-verdiana, seguindo trilha metafórica sugerida por Corsino Fortes, pode transformar a chuva - "esta noiva de usura", com sua "corola de ausência" (Ibidem, p. 202) e seios murchos - em úberes plenos: "As ilhas são cabras/ com úberes na via Láctea (Ibidem, p. 130).

Em coro com Filinto Elísio, representando a trajetória traumática, Corsino propõe que, como a cabra, ao "comer a terra, comer a terra, comer a terra" (FORTES, 2001, p. 57), as bocas vazias cabo-verdianas suturem feridas e alcancem o verde da secura, transfigurando a fome em fonte, a topia em entropia, a odisseia da carência numa ode-ceia: "Gozemo-las, as ilhas. Fome de comê-las. Sede de bebê-las. Ó de ceia das i_lhas...” (ELÍSIO, 2011, p. 14). Em suma, para sintetizar o móvel deste ensaio, a literatura, como ressalta Edgar 
Barbosa no prefácio a Famintos (de Luís Romano), pinta cenas e criaturas com dignidade e comovente solidariedade tal que, participando da identificação endocríptica, nós, os leitores, "sentimos que estamos a abraçar um povo".

Este é exatamente o sentimento que me envolve há trinta e sete anos. Meu trabalho tem sido uma forma de abraçar um povo e um país, parecido com o meu, sofrido, mas forte como o meu. O amor estético se fez, nessa longa convivência, corpo e carne. Hoje, é um amor maduro, pelo cheiro da terra, pelo vento, pela seca e pela alegria da chuva, quando esta, poeticamente, abençoa o agreste chão.

\section{Referências bibliográficas}

ABRAHAM, Nicolas; TOROK, Maria. Luto ou Melancolia. In: Abraham, N. \& Torok, M. A Casca e o núcleo. São Paulo: Escuta: 1995, p. 243-257.

ASSARÉ, Patativa do (Antônio Gonçalves da Silva). A Triste partida. In: Cante lá que eu canto cá. Petrópolis: Vozes, 1978. Disponível em <http://www.usinadeletras. com.br/exibelotexto.php? $\operatorname{cod}=7813 \&$ cat $=$ Cordel\&vinda $=S>$. Acesso em junho de 2012.

BARBOSA, Jorge. Caderno de um ilhéu. Lisboa: Agência Geral do Ultramar, 1956. - Obra poética. Lisboa: Imprensa-Nacional-Casa da Moeda, 2002.

BENJAMIN, Walter. A obra de arte na época de suas técnicas de reprodução. In: BENJAMIN, W.; HORKHEIMER, M.; ADORNO, T. W.; HABERMAS, J. Textos escolhidos. Trad. de José Lino Grünnewald. 2. ed. São Paulo: Abril Cultural, 1983.

BOHLEBER, Werner. Die Entwicklung der Traumatheorie in der Psychoanalyse. Psyche-Z Psychoanalyse, 54, 2000, p. 797-839.

CANDIDO, Antonio. Degradação do espaço. In: Revista de Letras. Assis, vol. 14, p. 7-36, 1972.

. Formação da literatura brasileira: momentos decisivos. 11 ed. Rio de Janeiro: Ouro sobre Azul, 2007.

CARREIRA, António. Cabo Verde (aspectos sociais. Secas e fomes no século XX). Lisboa; Cabo Verde: Ulmeiro, 1984.

CYTRYNOWICZ, Roney. O silêncio do sobrevivente: diálogo e rupturas entre memória e história do Holocausto. In: SELIGMANN-SILVA, Márcio (Org.). História, Memória, Literatura: o testemunho na Era das Catástrofes. Campinas: Ed. Unicamp, 2003, p. 125-140.

ELÍSIO, Filinto. Me_xendo no baú. Vasculhando o U. Lisboa: Letras Várias, 2011.

FILIPE, Daniel. Pátria, lugar de exílio. Lisboa: Presença, 1974. 
FOSTER, Hal. The return of the real. The avant-garde at the end of the century. London; Cambridge: MIT Press, 1996.

GINZBURG, Jaime. Autoritarismo e literatura: a história como trauma. Santa Maria: Revista Vidya, 2000. Disponível em <http://sites.unifra.br/Portals/35/Artigos/2000/33/autoritarismo.pdf.> Acesso: abril de 2012.

HERNANDEZ, Leila L. Os filhos da terra do Sol: a formação do estado-nação em Cabo Verde. São Paulo: Summus, 2002.

KRISTEVA, Julia. Pouvoirs de l'horreur. Essai sur l'abjection. Paris: Éditions du Seuil, 1980. LINS, Osman. Lima Barreto e o espaço romanesco. São Paulo: Ática, 1976.

MELO NETO, João Cabral de. Antologia poética. 3. ed. Rio de Janeiro: José Olympio, 1975 , p. 114-122.

POULET, Georges. O espaço proustiano. Trad. Ana Luiza B. Martins Costa. Rio de Janeiro: Imago, 1992.

RAMOS, Graciliano. Vidas secas. 48 ed. Rio de Janeiro, Record, 1981. Posfácio de Álvaro Lins.

Infância: memórias. 2. ed. Rio de Janeiro: José Olympio, 1952.

ROMANO Luís. Famintos: romance de um povo. Natal: Leitura, 1962.

SANTOS, Milton. A natureza do espaço: técnica e tempo, razão e emoção. São Paulo: Editora da Universidade de São Paulo, 2008.

SELIGMANN-SILVA, Márcio. História como trauma. In: NESTROVSKI, A.; SELIGMANN-SILVA, M. (Org.). Catástrofe e representação. São Paulo: Escuta, 2000, p. 73-98. . Narrar o trauma - a questão dos testemunhos de catástrofes históricas. Psicologia Clínica. Rio de Janeiro, vol. 20, N. 1, 2008, p. 65 - 82.

História, Memória, Literatura. O testemunho na era das catástrofes. Campinas: Editora da UNICAMP, 2003.

SOUSA, Henrique Teixeira de. Dragão e eu. In: Antologia da fição cabo-verdiana contemporânea. Selec. Baltasar Lopes. Praia: Edições Henriquinas-Achamento de Cabo Verde, 1960, p. 257-276.

SOUSA, Mário Lúcio. Nascimento de um mundo. Praia: Instituto Caboverdiano do Livro, 1991.

TAVARES, Eugénio. Poesia, conto e teatro. Praia, Instituto Caboverdiano do Livro e do Disco, 1996, p. 75.

TOLENTINO, Luís. Terra gritante. Praia: Grafedito, s.d.

VIEIRA, Arménio. Poemas. Mindelo: África, 1981, p. 14-15. . Mitografias. Mindelo: Ilhéu, 2006, p. 25-26.

Recebido em 03 de julho e aprovado em 10 de outubro de 2012. 